\title{
PARTIAL CHARACTERISATION OF ESCHERICHIA COLI HAEMOLYSIN
}

\author{
R. P. RenNiE* AND J. P. ARButhNotT $\dagger$ \\ Department of Microbiology, Alexander Stone Building, University of Glasgow, \\ Garscube Estate, Bearsden, Glasgow
}

\section{Plate V}

THE haemolytic activity of Escherichia coli has been investigated by only a few authors. Although there are many reports in the literature about haemolytic $E$. coli, most authors have merely noted that haemolytic strains were isolated. Lovell and Rees (1960) and Smith (1963) first demonstrated the production of an extracellular haemolysin (designated $\alpha$-haemolysin by Smith) in an alkaline meat-extract broth. Smith (1963) showed also that a cell-associated haemolysin (designated $\beta$-haemolysin) was produced by some strains. Other investigators (Snyder and Koch, 1966; Snyder and Zwadyk, 1969; Short and Kurtz, 1971) observed extracellular haemolytic activity when a strain of serogroup 06 was grown in chemically defined medium.

There is little information about the purification of $E$. coli $\alpha$-haemolysin. Zwadyk and Snyder (1971), like Lovell and Rees (1960), were unable to recover haemolytic activity after dialysis of ammonium-sulphate precipitates. Short and Kurtz (1971) found that two peaks of haemolytic activity appeared after chromatography of culture filtrates on Sephadex G-200 and Sepharose 6B. However, they gave no indication of the extent of purification and the activity of their starting material was low.

Only one author, Smith (1963), has investigated the biological properties of $\alpha$-haemolysin. He observed that the toxin was active against a range of erythrocyte species, that large amounts of haemolysin were required to kill mice and rabbits after intravenous injection, and that haemolytic culture filtrates did not cause dermonecrosis in the skin of rabbits or guinea-pigs. The haemolysin was unreactive after intragastric administration to rabbits.

In the present study we have attempted to clarify some of the deficiencies of previous work. Our main objectives were as follows: $(a)$ to produce large amounts of high-titre $\alpha$-haemolysin, $(b)$ to purify and characterise this agent, and $(c)$ to investigate the biological properties of $\alpha$-haemolysin in preparations with high specific activities. In an accompanying paper, the kinetics of erythrocyte lysis by $\alpha$-haemolysin are reported (Rennie, Freer and Arbuthnott, 1974).

Received 25 Apr. 1973; accepted 6 July 1973.

* Present address: Microbiology Department, Sunnybrook Hospital, University of Toronto, 2075 Bayview Avenue, Toronto, Ontario, Canada.

$\dagger$ Present address: Department of Bacteriology, University of Glasgow, Royal Infirmary, Glasgow, G4 OSF.

J. MED. MICROBIOL.-VOL. 7 (1974) 


\section{MATERIALS AND METHODS}

$E$. coli strains. The strains of $E$. coli used were isolated from clinical human infections. Cultures were maintained by monthly passage on nutrient-agar slopes after isolation of single haemolytic colonies from sheep-erythrocyte-agar plates. E. coli strain 25238 (serotype 019:B7, and of unknown flagellar type) was used for large-scale production of $\alpha$-haemolysin.

Haemolysin production. The growth from 12-hour nutrient-agar-slope cultures of the producing strain was used to inoculate four or six 2-1 flanged Erlenmeyer flasks each containing $500 \mathrm{ml}$ of Oxoid Nutrient Broth no. 2 and $0.2 \%$ (w/v) glucose. The initial inoculum was adjusted so that each flask contained approximately $2 \cdot 5 \times 10^{8}$ viable cells per $\mathrm{ml}$. The cultures were grown at $37^{\circ} \mathrm{C}$ in an orbital shaking incubator (Gallenkamp, London) at a shaking speed of 150 r.p.m. After 2 or 3 hours the cultures were harvested by centrifugation at $22,000 \mathrm{~g}$ for $15 \mathrm{~min}$. at $4^{\circ} \mathrm{C}$. The supernatant fluid was filtered through a Millipore membrane (Millipore, London) of $0.45 \mu \mathrm{m}$ porosity under positive nitrogen pressure. All filtrates were checked for sterility by plating on to MacConkey's and nutrient agar media.

Purification. A three-stage procedure was employed for purification of $\alpha$-haemolysin. All procedures were done at $4^{\circ} \mathrm{C}$. Stage I: solid ammonium sulphate was added with stirring to haemolytic culture filtrates to a final concentration of $50 \%(w / v)$. After 18 hours the fluid was centrifuged at $5000 \mathrm{~g}$ for $20 \mathrm{~min}$. The precipitate was dissolved in a minimal volume of distilled water and was dialysed for 6 hours against three changes of 20 volumes of distilled water adjusted to $p \mathrm{H} 8.0$ with $0.5 \mathrm{~N} \mathrm{NaOH}$. Stage II: the ammonium sulphate dialysate was precipitated by dialysis against three changes of 20 volumes of $0.005 \mathrm{M}$-acetate buffer, $p \mathrm{H} \mathrm{4.6}$ (Cruickshank, 1969). The fluid was centrifuged at $5000 \mathrm{~g}$ for $20 \mathrm{~min}$. and the

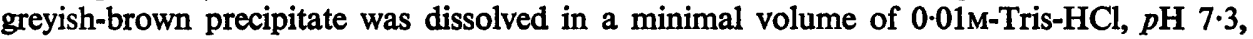
which contained $0.1 \mathrm{M} \mathrm{NaCl}$. This material was stored at $-20^{\circ} \mathrm{C}$ until required. Stage III: Sephadex G-200 (Pharmacia, Uppsala, Sweden) was swollen in distilled water for 5 hours

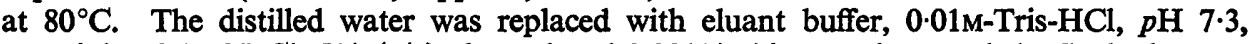
containing $0.1 \mathrm{M} \mathrm{NaCl}, 5 \%(\mathrm{v} / \mathrm{v})$ glycerol and $0.001 \%$ thiomersalate, and the Sephadex was washed four times to remove fines. The Sephadex was poured into a Pharmacia K26/100 column fitted with flow adaptors and a Mariotte flask. The void volume (Vo) of this column, determined by means of Blue Dextran 2000 (Pharmacia) was $145 \mathrm{ml}$. Sample volumes of $10 \mathrm{ml}$ of stage-II $\alpha$-haemolysin ( $35 \mathrm{mg}$ protein) were applied to the column and, after $100 \mathrm{ml}$ of eluate had passed through the column, 5-ml fractions were collected in a LKB 700 Ultrorac fraction collector (LKB Produkter, Sweden). The flow rate was maintained at $15-18 \mathrm{ml}$ per hour ( $3 \mathrm{ml}$ per $\mathrm{cm}^{2}$ per hour).

Haemolytic activity. Sheep blood was harvested from black-faced mountain ewes and was used within 3 days of collection. The blood was washed three times in sterile saline

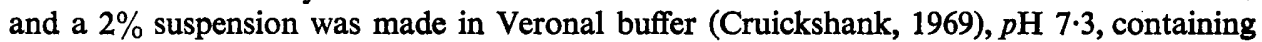
$10 \mathrm{mM} \mathrm{CaCl}$ (VC buffer). Standardisation of erythrocyte suspensions was performed by lysis of a sample of the $2 \%$ suspension with a small amount of saponin. The lysed portion was diluted four-fold with distilled water and the extinction (E) was measured in a Unicam SP600 spectrophotometer (Pye-Unicam, England) at an E of $545 \mathrm{~nm}$ in glass cells of 0.5 -cm light path. An $\mathrm{E}_{545}$ of 0.50 was considered to indicate a standardised $2 \%$ suspension of sheep erythrocytes (SRBC). Other erythrocyte species were treated in the same way. Haemolytic activity was determined by making doubling dilutions of 0.5 -ml portions of $\alpha$-haemolysin in $0.5-\mathrm{ml}$ volumes of VC buffer and adding $0.5 \mathrm{ml}$ of $2 \%$ SRBC to each tube. After 1 hour at $37^{\circ} \mathrm{C}$, the $50 \%$ end-point was determined spectrophotometrically at $545 \mathrm{~nm}$ on supernates that had been diluted with an equal volume of distilled water. One haemolytic unit (HU) is defined as the reciprocal of the dilution of haemolysin that causes $50 \%$ haemolysis under the conditions of the assay.

Chemical estimations. Protein was estimated by the method of Lowry et al. (1951); bovine serum albumin was used as a standard. The methods of Nelson (1944) and Scott and Melvin (1961) were employed for the detection of hexose and reducing sugars, and assays for total and inorganic phosphorus were made by a modified Allen method (Allen, 1940). The content of DNA was estimated by the method of Burton (1956).

Neutralisation tests. Antiserum to stage-II $\alpha$-haemolysin was prepared in rabbits 
according to the schedule of Gallop et al. (1966). Before use the antiserum was inactivated by heating at $56^{\circ} \mathrm{C}$ for $30 \mathrm{~min}$. For qualitative neutralisation tests, wells $(1 \mathrm{~cm} \times 4 \mathrm{~cm})$ were prepared in sheep-erythrocyte-agar-overlay medium (Rennie, 1973) and were filled with antiserum. The antiserum was allowed to diffuse into the medium and haemolytic strains of $E$. coli were then streaked at right-angles to the wells. After overnight incubation at $37^{\circ} \mathrm{C}$, plates were checked for zones of inhibition of haemolysis. More precise determinations of the potency of antisera were made by means of a neutralisation test in tubes. To doubling dilutions of antiserum in $0.5-\mathrm{ml}$ volumes of $\mathrm{VC}$ buffer were added $0.2-\mathrm{ml}$ volumes of VC buffer containing $20 \mathrm{HU}$ of $\alpha$-haemolysin. After storage of the toxinantitoxin mixtures for 1 hour at $4^{\circ} \mathrm{C}, 0.3 \mathrm{ml}$ of $3 \%$ SRBC suspension was added to each tube and the mixtures were incubated for 1 hour at $37^{\circ} \mathrm{C}$. The last tube showing complete neutralisation was taken as the end-point; the number of anti-haemolytic units was recorded as the antiserum titre multiplied by the number of haemolytic units used in the test.

Double diffusion tests. Diffusion tests in gel were performed by the method of Crowle (1958) on microscope slides fitted with Perspex coverslips. A layer of $0.75 \%$ Ionagar (Oxoid) in barbitone buffer ( $0.04 \mathrm{M}$ sodium diethyl barbituric acid, $p \mathrm{H} 8.3$ ), was applied under the coverslips. Undiluted antiserum and preparations of $\alpha$-haemolysin were applied to the slides through holes drilled in the coverslips and, after 24 hours at room temperature in a moist chamber, the slides were washed gently overnight in $0.01 \mathrm{M}$ phosphate buffer, $p \mathrm{H} \mathrm{7.5}$. Staining was performed for $15 \mathrm{~min}$. with saturated nigrosine in $2 \%(\mathrm{v} / \mathrm{v})$ acetic acid and the agar gels were de-stained and preserved by washing in a solution of $2 \%$ acetic acid in $1 \%(\mathrm{v} / \mathrm{v})$ glycerol.

Disk-gel electrophoresis. A modification of the method of Neville (1967) was used for electrophoresis in the presence of sodium dodecyl sulphate (SDS) and urea. Separating gels contained $3.5 \%(\mathrm{w} / \mathrm{v})$ acrylamide (BDH, Poole), $0.2 \% \mathrm{NN}^{\prime}$-methylenebisacrylamide (BDH, Poole) and $9 \mathrm{M}$ urea. No stacking gel was used. The upper tank buffer contained $8.3 \%(\mathrm{w} / \mathrm{v})$ glycine and $6 \mathrm{M}$ urea, $p \mathrm{H} 4.9$; the lower tank buffer was glacial acetic acid adjusted to $p \mathrm{H} 2.7$ with $1 \mathrm{M} \mathrm{KOH}$. Samples of $\alpha$-haemolysin were made up in $8.3 \%(\mathrm{w} / \mathrm{v})$ glycine and $6 \mathrm{M}$ urea; gels, buffers and samples were made $2 \%(\mathrm{w} / \mathrm{v})$ with SDS. Horse heart cytochrome $c$ (Koch-Light, Colnbrook, Bucks), molecular weight $=12,400$, was used as tracking dye. Electrophoresis was performed at $1.5 \mathrm{~mA}$ per gel. Fixation and staining were done overnight in a solution containing $1 \%(\mathrm{w} / \mathrm{v})$ amido black, $10 \%(\mathrm{v} / \mathrm{v})$ acetic acid and $50 \%(\mathrm{v} / \mathrm{v})$ methanol. Rehydration of gels was performed in $7 \%(\mathrm{v} / \mathrm{v})$ acetic acid; thereafter, they were destained by electrophoresis at $6 \mathrm{~mA}$ per gel. Marker proteins employed by McNiven, Owen and Arbuthnott (1972) were run under identical conditions in an attempt to estimate the molecular size of $E$. coli $\alpha$-haemolysin.

\section{RESULTS}

\section{Production of E. coli $\alpha$-haemolysin}

Of several different complex media, including meat-extract broth (Smith, 1963), only nutrient broth allowed consistent production of high-titre $\alpha$ haemolysin over a short incubation period. A typical example of growth and haemolysin production in this medium is shown in fig. 1. In unshaken cultures or in medium from which glucose was omitted, amounts of $\alpha$-haemolysin were five to 10 times lower. In this study $\alpha$-haemolysin was not detected in chemically defined medium (Snyder and Koch, 1966). Five additional strains of $E$. coli were compared with strain 25238 for production of $\alpha$-haemolysin in nutrient-broth medium. Of these, only one strain, no. 15370, did not elaborate $\alpha$-haemolysin.

To test the idea of Inukai and Kodama (1965) that large proteins contained in culture media are related to the release of $\alpha$-haemolysin from whole cells 
rather than to its synthesis, nutrient broth was filtered through a "Diaflo" ultrafiltration membrane (Amicon Corp., USA) having a molecular weight exclusion-limit of $1 \times 10^{5}$ daltons. Fig. 2 shows the levels of $\alpha$-haemolysin produced when strain 25238 was grown in the fluid retained by the membrane, the filtrate and complete nutrient broth medium. All media were adjusted to the same volume and protein content before inoculation and each medium

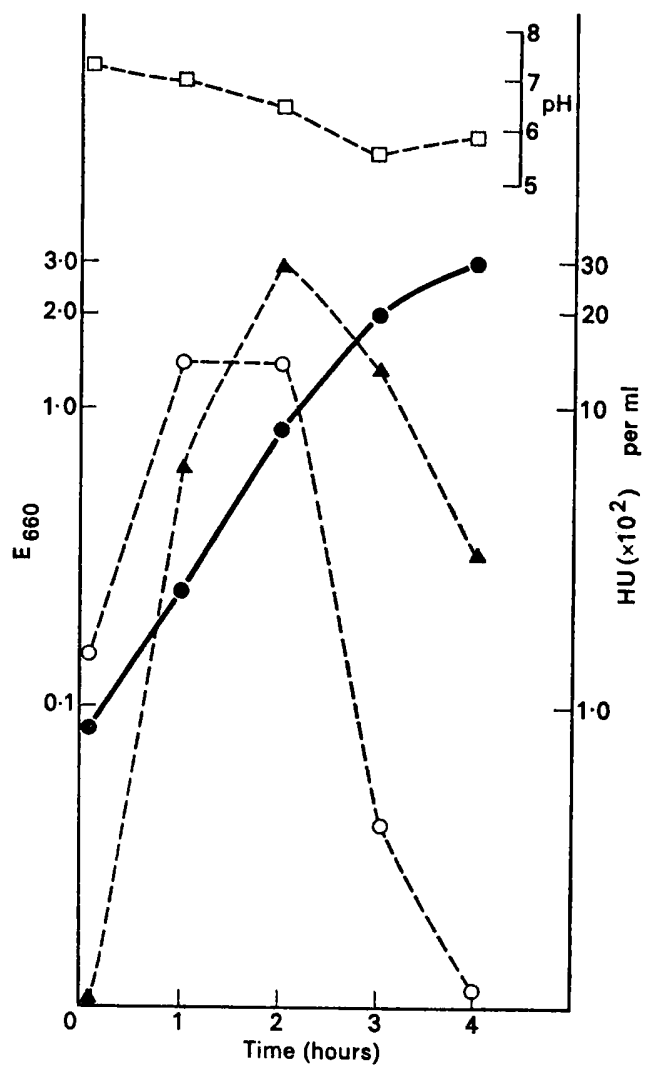

Fig. 1.-Production of $\alpha$-haemolysin and $\beta$-haemolysin by strain 25238 in nutrient broth:

growth measured by extinction at $660 \mathrm{~nm} ; \Delta---\Lambda \alpha$-haemolytic activity; $0---0 \beta$-haemolytic activity; $\square---\square p \mathrm{H}$ of culture filtrates.

contained $0 \cdot 2 \%(w / v)$ glucose. Production of $\alpha$-haemolysin was enhanced by large molecular-weight components contained in nutrient broth but not by substances in the medium having a molecular weight lower than $1 \times 10^{5}$ daltons. The rates of growth in these media were identical.

\section{Purification of $\alpha$-haemolysin}

The haemolysin was purified in three stages, as mentioned previously. It was found that precipitation of culture filtrates with $30-35 \%(\mathrm{w} / \mathrm{v})$ ammonium sulphate yielded only a small fraction of the haemolytic activity; $50 \%(\mathrm{w} / \mathrm{v})$ ammonium sulphate saturation was sufficient for complete precipitation of 
$\alpha$-haemolysin. No loss of activity was observed after dialysis at any stage of purification.

Gel filtration of stage-II haemolysin through Sephadex G-200 resulted in the consistent appearance of two closely associated peaks of haemolytic activity if $5 \%(\mathrm{v} / \mathrm{v})$ glycerol was included in the eluant buffer (fig. 3). One peak, corresponding to peak $A$, was seen if glycerol was omitted from the system. It is probable that glycerol retards aggregation of $\alpha$-haemolysin in

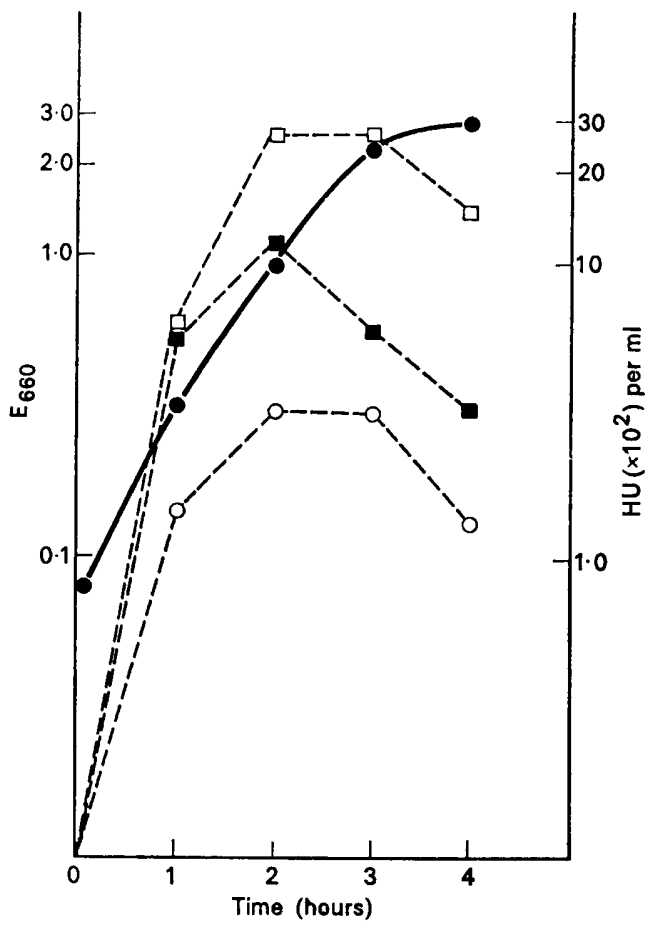

FIG. 2.-The effect of ultrafiltered components of nutrient broth on $\alpha$-haemolysin production: growth measured by extinction at $660 \mathrm{~nm}$ (the same in all media); $0--0 \alpha$-haemolytic activity in " Diaflo " membrane filtrate; $---\square \alpha$-haemolytic activity in complete nutrient broth; $\square---\square \alpha$-haemolytic activity in fluid retained by "Diaflo" membrane.

its purified form. In addition, significant reduction in the haemolytic activity of peak fractions was observed if $0 \cdot 1 \mathrm{M} \mathrm{NaCl}$ was omitted from the buffer.

From table I, which gives a summary of the purification procedure, it can be seen that exceedingly large increases in specific activity were obtained by these methods. It is important to note that activation of haemolysin during stages I and II was responsible for the apparently high percentage of recovered activity after Sephadex-gel filtration.

Electrofocusing proved unsuitable for purification of $\alpha$-haemolysin. Although recovered activity was good $(70 \%)$, the haemolysin precipitated at its iso-electric point $(p I=4 \cdot 6)$ and was difficult to recover without contamination by other non-haemolytic components. Nevertheless, it is noteworthy that, by the methods used, a level of purification was achieved that has not been reported previously. 


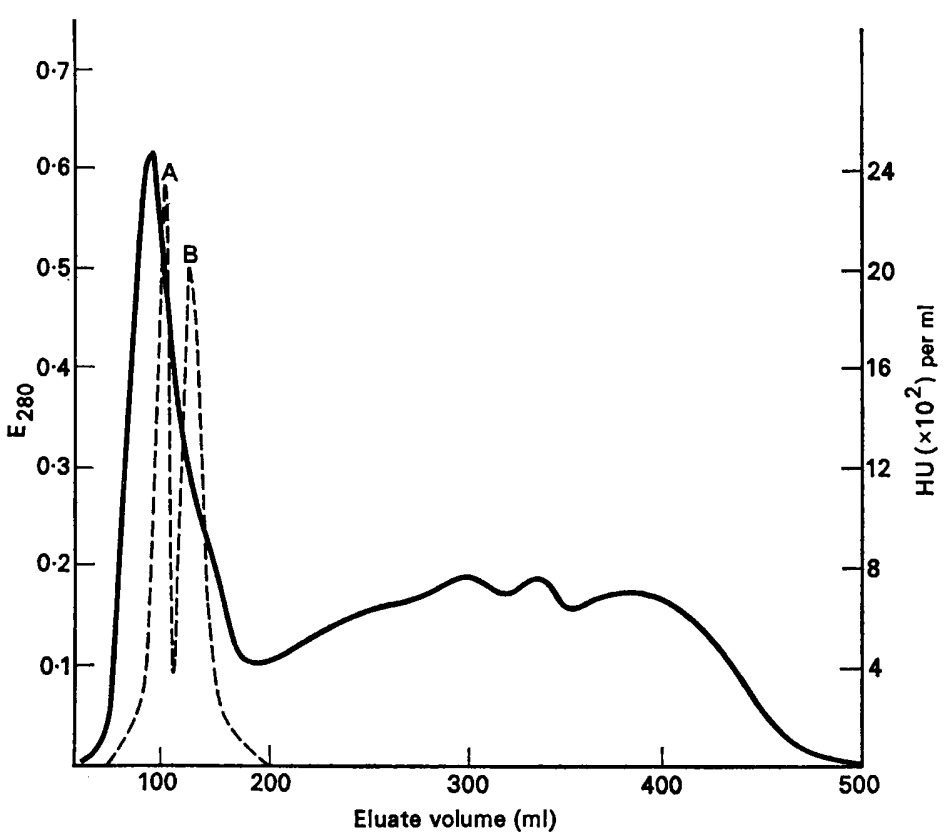

FIG. 3.-Gel filtration of stage-II $\alpha$-haemolysin on Sephadex G-200 with eluant buffer containing $5 \%(\mathrm{v} / \mathrm{v})$ glycerol: - extinction at $280 \mathrm{~nm} ;---\alpha$-haemolytic activity.

TABLE I

Summary of the standard purification procedure

\begin{tabular}{|c|c|c|c|c|c|c|}
\hline $\begin{array}{c}\text { Stage of } \\
\text { purification }\end{array}$ & $\underset{(\mathrm{ml})}{\text { Volume }}$ & $\begin{array}{l}\text { Total activity } \\
\left(\text { HU } \times 10^{3}\right)\end{array}$ & $\begin{array}{c}\text { Protein } \\
\text { (mg per ml) }\end{array}$ & $\begin{array}{l}\text { Specific activity } \\
\text { (HU per mg) }\end{array}$ & $\begin{array}{l}\text { Increase in } \\
\text { specific } \\
\text { activity }\end{array}$ & $\begin{array}{l}\text { Percentage } \\
\text { recovery }\end{array}$ \\
\hline $\begin{array}{l}0 \\
\text { I } \\
\text { II } \\
\text { III* }\end{array}$ & $\begin{array}{r}1750 \\
125 \\
85 \\
10\end{array}$ & $\begin{array}{r}5250 \\
18,750 \\
72,250 \\
4000\end{array}$ & $\begin{array}{r}11.6 \\
19.7 \\
3.6 \\
0.4\end{array}$ & $\begin{array}{r}260 \\
7600 \\
236,000 \\
1,000,000\end{array}$ & $\begin{array}{r}\times 29 \\
\times 907 \\
\times 3850\end{array}$ & $\begin{array}{r}357 \\
1376 \\
76\end{array}$ \\
\hline
\end{tabular}

- Pooled activities of peak fractions A and B were used to determine specific activity.

$\dagger$ Recovered activity at each stage compared with activity in original culture filtrate (stage 0 ).

\section{Identity of the haemolysin}

Purified $\alpha$-haemolysin contained $95 \%$ protein by weight. Hexose and reducing sugars, DNA and organic phosphorus were not detected, and less than $0.1 \%$ was accounted for by inorganic phosphate. The possible presence of small amounts of insoluble lipids cannot be discounted. As shown in fig. 4, two antigenic components were contained in stage II and G-200-peak fraction-A preparations. The minor precipitin line adjacent to the antigen well is probably due to a large molecular-weight component of the medium that was not removed by Sephadex chromatography. 
The haemolysin was heat labile; total inactivation occurred in $30 \mathrm{~min}$. at $56^{\circ} \mathrm{C}$. Purified preparations could be stored at $-20^{\circ} \mathrm{C}$ for more than 1 week without significant loss of activity. In the presence of trypsin or pronase (200 $\mu \mathrm{g}$ per $\mathrm{ml}$ ) complete inactivation was evident within $20 \mathrm{~min}$. Also, overnight storage in 3 to $6 \mathrm{M}$ urea caused $60-90 \%$ reduction in haemolytic titre.

Estimation of the molecular weight of $\alpha$-haemolysin required indirect methods, because elution with the void volume of Sephadex G-200 gave a minimum value of at least $2 \times 10^{5}$ daltons. As shown in fig. 5, purified $\alpha$-haemolysin did not enter acrylamide gels in the presence of SDS and urea, indicating that the haemolysin is not easily dissociated into subunits. Estimation of the

TABLE II

Haemolytic spectrum of $E$. coli $\alpha$-haemolysin

\begin{tabular}{lc}
\hline Erythrocyte species & \multicolumn{2}{c}{ Relative activity (\%)* } \\
\hline Sheep & 100 \\
Rabbit & 100 \\
Baboon & $83 \cdot 3$ \\
Cat & 75 \\
Dog & 66 \\
Cow & 62.5 \\
Horse & 59 \\
Rat & 50 \\
Human (AB) & 27 \\
Mouse & 20.8 \\
Fish: cod & $0 \cdot 8$ \\
$\quad$ haddock & $0 \cdot 08$ \\
$\quad$ saithe & $0 \cdot 04$ \\
\hline \multicolumn{2}{c}{ * Sheep erythrocytes as $100 \%}$.
\end{tabular}

diffusion coefficient (Allison and Humphrey, 1960) gave a value of $2.4 \times 10^{-7}$ $\mathrm{cm}^{2}$ per sec. which corresponded to an approximate molecular size of 5-6 $610^{5}$ daltons. Also, measurement of the diameters of haemolysin molecules incubated with calcium ions and negatively stained with $2 \%(\mathrm{w} / \mathrm{v})$ aqueous ammonium molybdate gave a molecular weight of $5.8 \times 10^{5}$ daltons (Green, 1969; Rennie et al., 1973).

\section{Biological properties}

The haemolysin was tested against several species of mammalian and three species of fish RBC. From table II it can be seen that sheep and rabbit RBC were most sensitive. However, the general impression was that $\alpha$ haemolysin had a broad haemolytic spectrum except that fish RBC were almost totally resistant.

With 32 haemolytic strains of $E$. coli, neutralisation of haemolysis by the agar-plate test was observed in all cases. Results for six of these strains are shown in fig. 6. As mentioned previously, one of these strains did not produce $\alpha$-haemolysin in liquid culture. By tube test it was found that the antiserum preparations contained about 80,000 anti- $\alpha$-haemolytic units. When this 
antiserum was tested against viable $E$. coli cells that exhibited only $\beta$-haemolytic activity, neutralisation of haemolysis was not observed.

The haemolysin was non-toxic for mice and rabbits after intravenous injection of $0 \cdot 3-3 \cdot 0 \mathrm{mg}$ of protein containing $50,000-500,000 \mathrm{HU}$. Intradermal injection of $\alpha$-haemolysin into the shaved backs of New Zealand White rabbits (Hyline, Cheshire) caused the appearance of hard palpable swellings which increased to a maximum at 18-20 hours and decreased thereafter. Heated toxin and diluent controls did not cause this effect. When examined for increased vascular permeability around injection sites by intravenous administration of Evans Blue dye (Gurr, London), according to the method of Moon and Whip (1971), zones of intense blue colour were not seen.

Preliminary experiments were performed with ligated intestinal segments in rabbits by the methods of Smith and Halls (1967). Dilatation and fluid accumulation were not observed in loops after the injection of either stage-II $\alpha$-haemolysin or strain 25238 . Nevertheless, when compared with control loops or with segments into which heated toxin had been injected, the test loops had a haemorrhagic appearance macroscopically. Furthermore, strain 25238 was recovered from the heart blood of rabbits given $c .10^{8}$ viable cells of this strain into a loop, whereas a non-haemolytic enteropathogenic strain, serotype 055:K59 (B5):H6, was recovered only from intestinal segments. This strain, however, did not cause fluid accumulation after injection into loops.

\section{Discussion}

High-titre $E$. coli $\alpha$-haemolysin was formed reproducibly in a glucosenutrient-broth medium. In contrast to the findings of Snyder and Koch (1966), $\alpha$-haemolysin was not produced in chemically defined medium. Because the extracellular haemolysin observed by these workers in defined medium was heat-stable, the suggestion of Muranyi and Juhasz (1971), that organic acids produced by $E$. coli strains in defined medium are responsible for haemolytic activity, must be considered.

Our findings agree with those of Inukai and Kodama (1965) that elaboration of $\alpha$-haemolysin is enhanced by large molecular-weight components of the medium. It is interesting to note that antibody to $\alpha$-haemolysin neutralised the zones of haemolysis produced by the six strains shown in fig. 6, yet one of these strains did not produce $\alpha$-haemolysin in liquid medium. This raises the question of the relationship between $\alpha$ - and $\beta$-haemolysin. Our data suggest the possibility that $\alpha$-haemolysin is a released form of $\beta$-haemolysin, and that this release is brought about by complexing of as yet unidentified large molecular-weight factors in the medium with cell-associated $\beta$-haemolysin. That different strains produced different amounts of $\alpha$-haemolysin in nutrient broth may reflect differences in the binding properties of $E$. coli haemolysin to structures on bacterial cell surfaces.

The observation of Zwadyk and Snyder (1971), that haemolytic activity was lost after dialysis, was not confirmed in this study. By our methods of purification, high-titre purified haemolysin was obtained consistently. Activation of the haemolysin during purification-stages I and II might be accounted 


\section{ESCHERICHIA COLI HAEMOLYSIN}

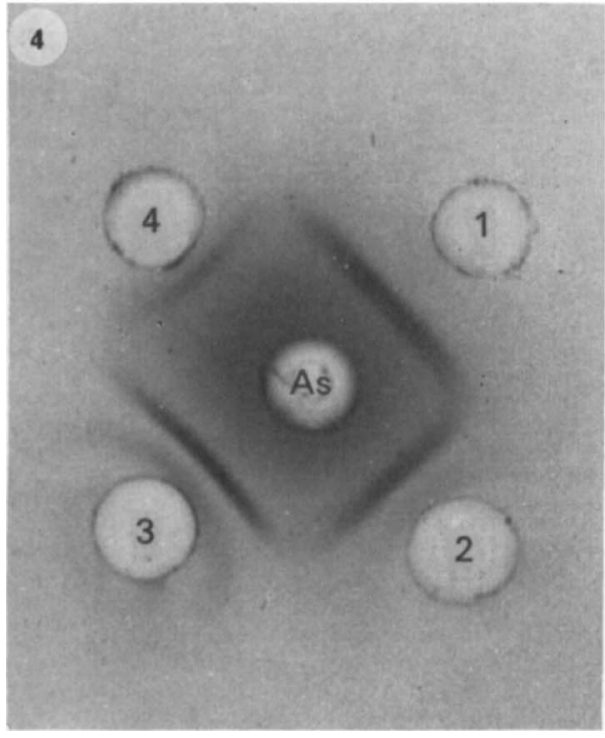

FIG. 4.-Microslide agar-gel diffusion of different $\alpha$-haemolysin preparations. As $=$ Antiserum to stage-II $\alpha$-haemolysin; $1=$ stage-I haemolysin; $2=$ stage-II haemolysin; $3=$ Sephadex G-200 peak fraction $A ; 4=$ Sephadex $G-200$ peak fraction $B$.

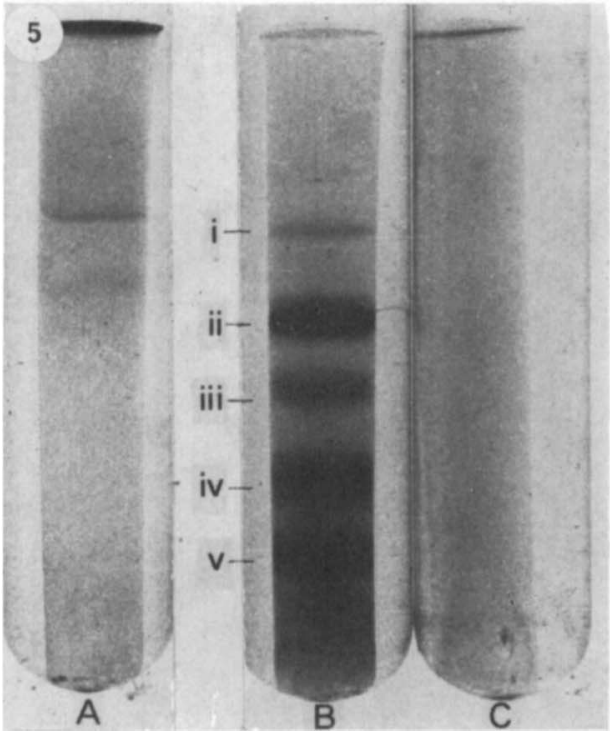

FIG. 5.-Urea-SDS polyacrylamide-gel electrophoresis of purified $E$. coli $\alpha$-haemolysin. A Sephadex G-200 peak fraction A. B. Marker proteins in urea-SDS system (i) hexokinase (ii) bovine serum albumin (iii) ovalbumin (iv) chymotrypsinogen $(v)$ cytochrome c. C. Blank gel.

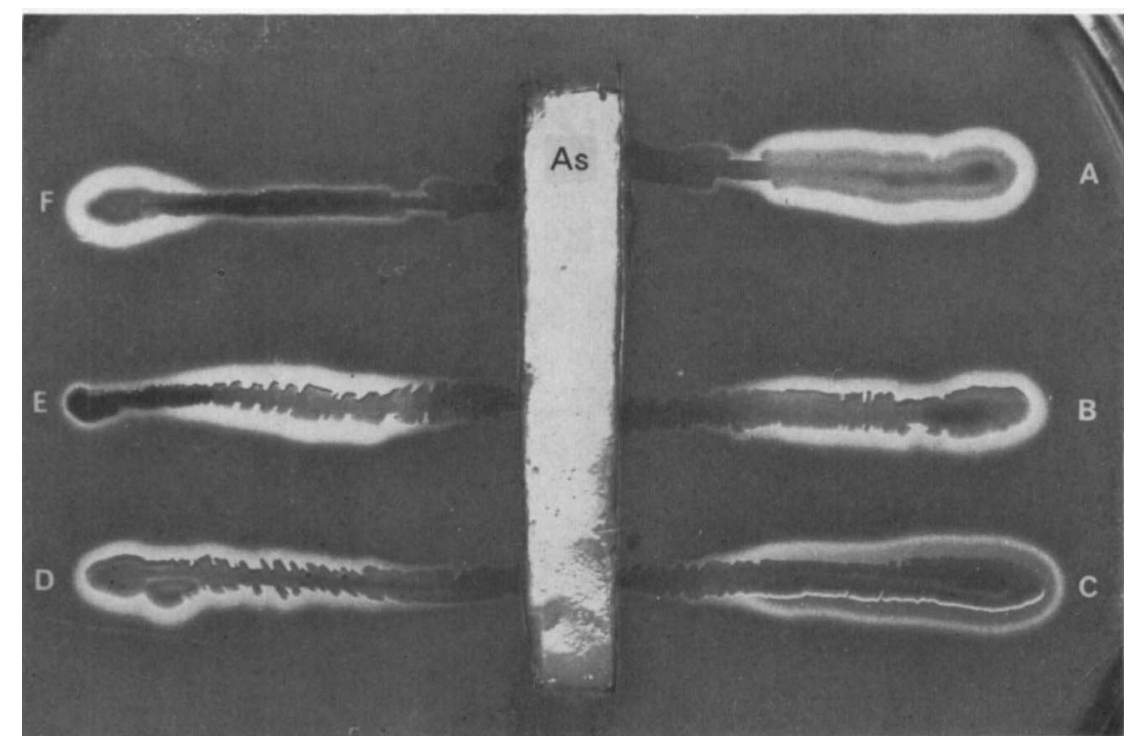

FIG. 6.-Neutralisation of the haemolytic activity of E. coli strains on erythrocyte agar plates. $\mathrm{As}=$ Antiserum to stage-II $\alpha$-haemolysin; $\mathrm{A}=$ strain 25238 , serotype O19:B7; $\mathrm{B}=$ strain 4748 , serogroup $\mathrm{O} 6 ; \mathrm{C}=$ strain 122 , serotype $\mathrm{O} 86: \mathrm{B} 7 ; \mathrm{D}=$ strain 189 , serotype $\mathrm{O} 128: \mathrm{B} 12$; $\mathrm{E}=$ strain 3829 , serogroup $\mathrm{O6} ; \mathrm{F}=$ strain 15370 , serotype $\mathrm{O} 18: \mathrm{B} 21$. 
for by three possible mechanisms: $(a)$ loss of an inhibitor, $(b)$ alteration in structure resulting in exposure of hidden active sites or altered affinity for calcium ions, or $(c)$ formation of biologically active subunits. The latter mechanism probably does not occur because haemolytic activity is lost in the presence of urea, an agent that causes unfolding of polypeptide chains (Reithel, 1963). Evidence obtained so far is insufficient to allow further conclusions about the operative mechanism.

Our results are consistent with the view that $\alpha$-haemolysin is a heat-labile protein having a very large molecular weight and that this protein does not readily dissociate into smaller subunits. It appears, therefore, that $E$. coli haemolysin is unique among bacterial cytolytic toxins; average molecular weights reported for most bacterial protein toxins are in the region of 2-6 $\times 10^{4}$ daltons. However, we must add a cautionary note, because the possibility cannot be discounted that part of the molecule consists of a carrier protein that binds firmly to the haemolysin during liberation from $E$. coli cells.

The lack of toxicity found after intravenous injection in mice and rabbits contrasts with the findings of Smith (1963), but may reflect differences in the purity of the preparations of $\alpha$-haemolysin that have been used. It is noteworthy that Smith (1963) also observed hard swellings at injection sites when filtered samples of $\alpha$-haemolysin were administered intradermally to rabbits. With respect to toxicity and the time-course of dermal swelling, $\alpha$-haemolysin appears to have properties in common with E. coli enterotoxin (Craig, 1972; Moon and Whip, 1971). However, our preliminary results with ligated intestinal loops suggest that $E$. coli haemolysin has no function in localised enteric infections. As discussed by Smith and Halls (1968) and as indicated by our finding that only the haemolytic strain of $E$. coli was invasive, the $E$. coli haemolysin is possibly a virulence factor in extra-intestinal infections such as bowel oedema disease of pigs.

\section{SUMMARY}

Large amounts of high-titre $E$. coli $\alpha$-haemolysin were produced in a nutrient broth medium. Production was enhanced by growth in a medium containing large molecular-weight components. The haemolysin was purified by " salting out " with ammonium sulphate precipitation at its iso-electric point $(p I=4 \cdot 6)$ and by chromatography on Sephadex G-200. Evidence is presented that the haemolysin is a large protein (approximate molecular weight $=580,000$ ) that was not easily dissociated into smaller subunits. Lethality in mice and rabbits was not observed after intravenous injection of $\alpha$-haemolysin, but hard swellings appeared at injection sites after the intradermal administration of active haemolysin preparations. The haemolysin did not cause fluid accumulation in ligated intestinal segments in rabbits.

The authors gratefully acknowledge the co-operation of Dr T. A. McAllister, Queen Mother's Hospital, Yorkhill, Glasgow, who supplied the strains of E. coli, and Mr I. Duncan, Department of Veterinary Surgery, University of Glasgow, who performed surgical techniques. This work was done while one of us (R. P. R.) was in receipt of a Medical Microbiology Studentship from the University of Manitoba, Canada. In part, this study was supported by grants from The Royal Society and the Scottish Home and Health Department. 


\section{REFERENCES}

Allen, R. J. L. 1940. The estimation of phosphorus. Biochem. J., 34, 858.

Allison, A. C. AND HUMPHREY, J. H. 1960. A theoretical and experimental analysis of double diffusion precipitin reactions in gels, and its application to characterization of antigens. Immunology, 3, 95 .

Burton, K. 1956. A study of the conditions and mechanism of the diphenylamine reaction for the colorimetric estimation of deoxyribonucleic acid. Biochem. J., $62,315$.

Craig, J. P. 1972. The enterotoxic enteropathies. Symp. Soc. gen. Microbiol., 22, 129.

Crowle, A. J. 1958. A simplified micro double-diffusion agar precipitin technique. $J$. Lab. clin. Med., 52, 784.

Cruickshank, R. 1969. In Medical microbiology, 11th ed., revised reprint, Edinburgh, p. 861.

Gallop, R. G. C., Tozer, B. T., Stephen, J. and Smtth, H. 1966. Separation of antigens by immunological specificity. Use of cellulose-linked antibodies as immunosorbents. Biochem. J., 101, 711.

Green, N. M. 1969. Electron microscopy of the immunoglobulins. Adv. Immun., 11, 1.

INUKAI, Y. AND KoDAma, H. 1965. Studies on hemolytic Escherichia coli of O139: a certain factor essential for hemolysin production. Jap. J. vet. Res., $13,87$.

Lovell, R. AND ReEs, T. A. 1960. A filterable haemolysin from Escherichia coli. Nature, Lond., 188, 755.

Lowry, O. H., Rosebrough, N. J., FarR, A. L. and Randall, R. J. 1951. Protein measurement with the folin phenol reagent. J. biol. Chem., 193, 265.

MCNiven, A. C., OWEN, P. AND ARBuThNotT, J. P. 1972. Multiple forms of staphylococcal alpha-toxin. J. med. Microbiol., 5, 113.

Moon, H. W. AND WHIP, S. C. 1971. Systems for testing the enteropathogenicity of Escherichia coli. Ann. N.Y. Acad. Sci., 176, 197.

MuRANYI, F. AND JuHASZ, S. 1971. Haemolytic effect of Escherichia coli cultures and their filtrates. Acta. vet. hung., 21, 355.

Nelson, N. 1944. A photometric adaptation of the Somogyi method for the determination of glucose. J. biol. Chem., 153, 375.

NeviLle, D. M. 1967. Fractionation of cell membrane protein by disc electrophoresis. Biochem. biophys. Acta., 133, 168.

Rerthel, F. J. 1963. The dissociation and association of protein structures. Adv. Protein Chem., 18, 124.

ReNNIE, R. P. 1973. Haemolytic activity of Escherichia coli. PhD Thesis, University of Glasgow.

Rennie, R. P., Freer, J. H. AND Arbuthnott, J. P. 1974. The kinetics of erythrocyte lysis by Escherichia coli haemolysin. J. med. Microbiol., 7, 189.

Scott, T. A. AND Melvin, E. H. 1961. In Experimental immunochemistry, 2nd ed., edited by E. A. Kabat and M. M. Mayer, Springfield, USA, p. 528.

ShorT, E. C. AND KURTz, H. J. 1971. Properties of the hemolytic activities of Escherichia coli. Infect. Immun., 3, 678.

SMITH, H. W. 1963. The haemolysins of Escherichia coli. J. Path. Bact., 85, 197.

SMITH, H. W. AND Halls, S. 1967. Observations by the ligated intestinal segment and oral inoculation methods on Escherichia coli infections in pigs, calves, lambs and rabbits. J. Path. Bact., 93, 499.

SMITH, H. W. AND Halls, S. 1968. The production of oedema disease and diarrhoea in weaned pigs by the oral administration of Escherichia coli: factors that influence the course of the experimental disease. J. med. Microbiol., 1, 45 .

SNYDER, I. S. AND KOCH, N. A. 1966. Production and characteristics of hemolysins of Escherichia coli. J. Bact., 91, 763.

SNYDER, I. S. AND ZWADYK, P. 1969. Some factors affecting the production and assay of Escherichia coli haemolysins. J. gen. Microbiol., 55, 139.

ZWADYK, P. AND SNYDER, I. S. 1971. Purification and kinetic studies of the hemolysin from Escherichia coli. Can. J. Microbiol., 17, 741. 